\title{
Alfabetización reflexiva, construcción permanente del pensamiento
}

\author{
María Evelinda Santiago Jiménez \\ Misael Murillo Murillo** \\ Bernardo Parra Vitorino*** \\ María Eugenia Lazcano Herrero****
}

\begin{abstract}
Resumen: La función de la educación es difundir las ventajas de vivir en sociedades democráticas, sin embargo, la diáspora de esas ventajas está articulada a intereses políticos y económicos globalizados; su misión: anestesiar a la sociedad para que observe en silencio el desmantelamiento de su proyecto de vida. La educación tradicional no fomenta la habilidad para leer la complejidad de esa realidad democrática. Se enfoca, principalmente, en aleccionar sobre las "ventajas" de la modernidad, donde la mayoría tiene como destino ser masas de asalariados y una minoría, "heredar" la élite. Este documento, propone que para leer esta realidad, la ciudadanía debe ser alfabetizada más allá de la mera técnica que sólo sirva para leer, memorizar y escribir manuales; particularmente la alfabetización debe ser: reflexiva, crítica, basada en el diálogo de saberes y permanente; pero, éticamente coordinada por docentes intelectuales.
\end{abstract} cente intelectual

Palabras clave: aprendizaje, alfabetización, reflexión, complejidad, do-

\section{Reflexive literacy, permanent building of thought}

\begin{abstract}
The role of education is to spread the benefits of living in democratic societies, however, the diaspora of those advantages is connected to globalized economic and political interests; their mission: to anesthetize society so it will silently observe the dismantling of its life project. Traditional education does not promote the ability to read the complexity of the democratic reality. It focuses primarily on lecturing about the "benefits" of modernity, where the majority is destined to be masses of employees, and a minority to "inherit" the elite. This document proposes that for reading this reality, citizens must be literate beyond mere technique that would only serve to read, memorize and write manuals, particularly literacy should be: thoughtful, critical, based on knowledge's dialogue and permanent; but, ethically coordinated by intellectual teachers.
\end{abstract}

Key words: learning, literacy, thinking, complexity, intellectual teacher

\footnotetext{
* Instituto Tecnológico de Puebla, Puebla, México. Email:_evelindasantiago@yahoo.com.mx, evelinda.santiago@gmail.com

** Instituto Tecnológico de Puebla, Puebla, México. Email: premi168@yahoo.com.mx

*** Instituto Tecnológico de Puebla, Puebla, México. Email: bernardoparra@hotmail.com

**** Instituto Tecnológico de Puebla, Puebla, México. Email: maru40@hotmail.com
} 


\section{Alfabetização reflexiva, construção permanente do pensamento}

Resumo: A função da educação é difundir as vantagens de viver em sociedades democráticas, no entanto, a diáspora dessas vantagens está articulada a interesses políticos e económicos globalizados; sua missão: anestesiar à sociedade para que observe em silêncio o desmantelamiento de seu projecto de vida. A educação tradicional não fomenta a habilidade para ler a complexidade dessa realidade democrática. Se enfoca, principalmente, em aleccionar sobre as "vantagens" da modernidade, onde a maioria tem como destino, ser massas de assalariados e uma minoria, "herdar” a elite. Este documento, propõe que para ler esta realidade, a cidadania deve ser alfabetizada para além da mera técnica que só sirva para ler, memorizar e escrever manuais; particularmente a alfabetização deve ser: reflexiva, crítica, baseada no diálogo de saberes e permanente; mas, eticamente coordenada por docentes intelectuais.

Palavras-chave: aprendizagem, alfabetização, reflexão, complexidade, docente intelectual

Recibido: 31.01.2010

Aceptado: 05.03.2010

$* * *$

\section{Introducción}

Se cree que un individuo está alfabetizado porque conoce o aprende la técnica de leer y escribir. Sin embargo, ésta no lo capacita para leer la complejidad de la realidad, mucho menos puede escribir sobre ella. Estas imposibilidades son resultado de la mística encerrada en la alfabetización tradicional: un adoctrinamiento que no permite vislumbrar las diferentes tonalidades de la realidad, tampoco permite decodificar los mitos creados con el objetivo oculto de beneficiar a unos cuantos. En este sentido, se puede decir que la complejidad social y ecológica sólo puede ser descifrada por ciudadanos que cuenten con elementos que les permitan "leerla" de manera crítica. Sólo así es posible, por ejemplo, diferenciar las acciones colectivas de resistencia, de las acciones globales para subyugar la conciencia. Una alfabetización más allá de la mera técnica de unir vocales y consonantes debe tener el carácter de diálogo, un diálogo que sirva para catalizar ciertos grados de cuidado de uno mismo ante la realidad. Por lo tanto, el proceso de alfabetización tiene que partir de una profunda comprensión de leer una realidad circunscrita en la complejidad (Freire, 1989). No es propicio el abandono de la técnica, sino la inclusión de valores democráticos y éticos como estrategias imbricadas en las técnicas de "aprehendizaje" con las que la ciudadanía pueda leer, escribir, vivir, participar y dialogar en un mundo complejo, enmarcado por la crisis ambiental y social.

Por otra parte, no se puede negar que la educación ha sido y es un instrumento poderoso de conocimiento y transformación de la sociedad. A través de ella, la humanidad ha dotado de bases a la sociedad para que busque estrategias para resolver problemas críticos, como sería la escasez 
de recursos, el hambre en el mundo y la procuración de mejores condiciones de bienestar para la humanidad. Sin embargo, también ha servido para adoctrinar a la sociedad, argumentando que es mejor ser modernos que tradicionales; una naturaleza muerta y en las vitrinas del mercado que un paisaje vivo e intacto; lo instantáneo que hacer historia; la acumulación de bienes suntuarios a mantener la frugalidad; entre otras premisas distribuidas a través de un curriculum oculto, manejado a través de símbolos.

Tampoco se puede negar que la educación ha sido la detonante que ha incrementado las dos características especiales del ser humano: la capacidad tecnológica para transformar los ecosistemas y la capacidad de transformar la realidad social a través de la generación de mitos. Por otro lado, si bien es cierto que la educación ha abierto las posibilidades para un conocimiento colectivo, su disposición para privilegiar el interés político y económico ha promovido la subyugación de sociedades y ecosistemas, comprometiendo las diferentes formas de vida en el planeta. Sólo la sociedad puede modificar esa disposición, ejerciendo su ciudadanía, manifestando su derecho a ser incluida en todas aquellas decisiones políticas que la afecten. Sin embargo, la sociedad aún no está preparada para hacer uso de este derecho. Una estrategia para que aprenda a ejercer su ciudadanía se encuentra en una alfabetización más allá de la mera técnica de aprender a leer y escribir, es decir, urge una alfabetización permanente y reflexiva que lleve al análisis crítico, para descubrir las verdades generadas en los espacios de control y poder; y que lleve, además, al aprendizaje para la organización y la participación ciudadana en la (re)invención de las políticas públicas.

\section{La educación tradicional}

Se pudiera pensar que las instituciones educativas tienen un "contrato" con la sociedad donde ellas se responsabilizan de la enseñanza de las ventajas que proporciona vivir en las sociedades democráticas; sin embargo, la democracia que difunden está desvirtuada porque hace referencia a un sistema de gobierno acoplado a ciertos elementos de la élite y apoyado en la comunidad comercial, los que controlan el Estado mediante el dominio de la sociedad privada, mientras que la sociedad observa en silencio (Chomsky 2007). La participación activa de la sociedad en la demanda de la (re)construcción de las políticas públicas es una amenaza para este tipo de "democracia", por eso le han dedicado mucho esfuerzo a la generación de políticas educativas que fortalezcan mitos con ideología ${ }^{1}$ etnocéntrica. Su distribución es realizada a través de maestros adoctrinados sobre el mantenimiento de los procesos de modernización e industrialización, que

\footnotetext{
${ }^{1}$ Acorde a Luis Villoro (2007[1985]:19) Ideología se define no sólo por su condicionamiento social, $[\ldots]$ sino también por la función objetiva que cumple, en las luchas sociales, para lograr o mantener el dominio de un grupo. [Por otra parte], ideológico resulta todo conjunto de creencias que promueven el poder político de un grupo o una clase determinados.
} 
tienen como hilo conductor la libertad y la democracia de la humanidad ${ }^{2}$; pero de corte capitalista, fuente de trabajo, consumistas y nuevos pobres (Bauman 2008[1998]). La colaboración - consciente o inconsciente - disciplinada de los maestros, es "pastoreada" por la esperanza de poder concursar por compensaciones económicas (becas académicas, puestos de autoridad, etc.) o pequeños privilegios que el sistema crea para mantenerlos en el rumbo "correcto".

El adoctrinamiento es un proceso que repetitivo que crea una conciencia colectiva, pero dividida con etiquetas que definen las funciones que cada individuo debe de realizar para mantener el sistema civilizatorio prevaleciente. Lo anterior marca a la sociedad y esta marca social está delineada por el hecho de que cada grupo social tiene un tipo de escuela propio, destinado a perpetuar en estos grupos una determinada función tradicional: directiva o instrumental (Gramsci, 2000), en otras palabras: jefes o subordinados. El sistema educativo se ha adecuado a los intereses políticos y económicos de una pequeña minoría; esta postura ha redundado en la formación de capital humano listo para entrar en las filas del sistema que fortalece la racionalidad capitalista. El ejercicio de cada una de las profesiones direccionadas para el mantenimiento del discurso del desarrollo (Escobar 1995), ha dado como resultado una crisis social y ecológica. Hoy se puede observar que es consecuencia de la crisis de un modelo económicotecnológico y cultural que ha depredado a la naturaleza y subyugado a las culturas alternas (Riechmann 2004).

La situación social cada vez más compleja y caótica cada día que pasa, pone al sistema educativo entre dos frentes políticos: por un lado, uno que la invita a seguir nutriendo el sistema económico hegemónico con "capital humano”, carente de habilidades para establecer diálogos reflexivos escritos y verbales; pero listo para puestos mal remunerados; y por el otro lado, aquel que la conmina a reorientar su doctrina hacia linderos incluyentes, plurales y respetuosos de la diversidad social y ecológica; donde el diálogo entre saberes dentro del aula, sea la parte fundamental de los análisis críticos de la realidad histórica y política de lo local, lo regional y lo nacional.

Sin embargo, la definición de la postura política actual es un peligro que acosa a la educación porque proviene de intereses externos a la misma educación, los que amenazan su autonomía en busca de cooptarla para sus propios fines e imponerle objetivos que le son ajenos (Bourdieu 2003). A partir de esa postura define como su fin más preciado, organizar aquello que conoce, sustituyendo todo lo relativo por lo absoluto, por poner un ejemplo podemos encontrar en la práctica los verbos observar, medir, predecir y controlar; estas metas pedagógicas justifican la acción violenta en pos de un mejoramiento continuo de nuestras condiciones de vida. Para ser

\footnotetext{
${ }^{2}$ Con esta ideología en mente se han diseñado nuevas herramientas para "normalizar” a la sociedad: la mejora continua, el posicionamiento y la certificación; asuntos básicos para acoplarse al sistema civilizatorio que prevalece en el planeta.
} 
congruente con ese fin, se convierte en una institución disciplinaria ${ }^{3}$, “una maquinaria de control que ha funcionado como un microscopio de la conducta; las divisiones tenues y analíticas que han realizado han llegado a formar, en torno a los hombres, un aparato de observación, de registro y de encauzamiento de la conducta” (Foucault 1975: 178).

Es importante hacer ver que las estructuras disciplinarias no matan, sino que dejan vivir al individuo, tampoco lo anulan, sino que lo hacen valioso. De hecho establecen un vínculo con él, esculpiéndolo para que aprehenda que cuando es más obediente, es más útil y mientras ponga toda su voluntad en ser más útil, ha sido y es más obediente. Curiosamente las disciplinas aplicadas no derrochan poder, porque no lo tienen, contrariamente, aumentan la fuerza del cuerpo humano (haciéndolo útil) al mismo tiempo encaminan esa fuerza (haciéndolo obediente). El producto de cuerpos útiles, dóciles y obedientes puede verse en el aula de clase donde los mesa_bancos están distribuidos de manera ordenada para que el profesor tenga una visión completa del salón de clase desde su estrado, puesto para observar los movimientos y controlar la obediencia del grupo. Además, clasifica a los alumnos por categorías, por ejemplo: los más atentos o los más distraídos, según el gusto del profesor. Los métodos utilizados en las escuelas tradicionales dan como resultado un adoctrinamiento de los alumnos para que estén listos para incursionar en otros espacios donde también reinan las técnicas disciplinarias.

Los mitos son la herramienta utilizada para el adoctrinamiento disciplinario, los que no son cuestionados porque ofrecen un retrato simplista de la realidad compleja; y son antirrealistas porque disfrazan la verdad (Chomsky 2007). De ahí que la enseñanza de la verdad y no la voluntad de la verdad ${ }^{4}$

\footnotetext{
${ }^{3}$ Por su parte, la labor de la disciplina es sancionar aquello que no se ajusta a la regla y sin lugar a dudas, a las desviaciones - a través de las graduaciones de los individuos y el establecimiento de sus diferencias se señalan las desviaciones, se jerarquizan las cualidades, sin que lo anterior signifique dejar de castigar y recompensar - La norma no es utilizada para la represión, sino que marca diferencias y jerarquiza, al mismo tiempo que homogeniza y excluye, para que los individuos se asemejen y así, definir una naturaleza humana que hace al hombre visible, diferenciable, calculable; pero, a su vez, el poder disciplinario se oculta, se hace anónimo y funcional, bajo indiscutibles verdades psicológicas. En consecuencia de todo este proceso de normalización disciplinaria, el individuo es una realidad fabricada por las estructuras de poder, una maquinaria que produce realidad, ámbitos de objetos y rituales de verdad. (Foucault 1975: 198).

4 "La voluntad de verdad, como los otros sistemas de exclusión, se apoya en un soporte institucional: está a la vez reforzada y reconducida por una densa serie de prácticas como la pedagogía, como el sistema de libros, la edición, las bibliotecas, como las sociedades de sabios de antaño, los laboratorios actuales. Pero es reconducida también, más profundamente sin duda, por la forma que tiene el saber de ponerse en práctica en una sociedad, en la que es valorizado, distribuido, repartido y en cierta forma atribuido. Recordemos, y a título simbólico únicamente, el viejo principio griego: que la aritmética puede muy bien ser objeto de las sociedades democráticas, pues enseña las relaciones de igualdad, pero que la geometría sólo debe ser enseñada en las oligarquías ya que demuestra las proporciones en la desigualdad.” (Foucault 2009[1973]:22).
} 
(Foucault 2009 [1973]) se supone una verdadera amenaza para el sistema doctrinal. Un maestro que se apega a la ideología del sistema doctrinal poco interés tiene en mencionar las irregularidades en la aplicación de las leyes que sostienen las actividades que mantienen la discriminación. Este es el caso de los pueblos originarios a quienes se les construyó una realidad que los hace invisibles porque son ignorados a través de procesos discriminatorios o de compasión, convirtiéndolos en una realidad olvidada. En este sentido, puede afirmarse que la construcción de la realidad histórica de la sociedad pasa por procesos políticos que están entretejidos en la trama más fina de la ideología del progreso económico y del dominio de la naturaleza. Enredar la historia ha sido una de las características que ha marcado a los procesos civilizatorios, básicamente la estrategia es utilizada para socavar a los Otros - los que no forman parte de la élite que domina las sociedades. Los mitos (re)crean la realidad para que sea distribuida a través de los canales institucionales, quienes se prestan para llevar a cabo el proceso de modelación de las sociedades. Regularmente los mitos etiquetan, distorsionan, discriminan y borran todo aquello que vaya en contra de los intereses establecidos por esa minoría que teme que la ciudadanía lea la realidad de manera crítica.

Es característico, en los pueblos que han sido colonizados, construir una realidad adecuada a los vencedores, en México, la historia oficial ha definido y descrito quiénes son y qué caracteriza a los así llamados indios, teniendo como plataforma la lógica del pensamiento occidental.

Para romper con este pensamiento y sentimiento hacia los pueblos originarios es necesario hacer una crítica de los valores morales, hay que poner alguna vez en entredicho el valor mismo de esos valores, y para esto se necesita tener conocimiento de las condiciones y las circunstancias en las que ellos surgieron, en las que se desarrollaron y modificaron (Foucault 2009[1973]). Los valores morales de las instituciones y las élites de la colonia aún se mantienen: por un lado se elogia la parte material, el esplendor de la civilización mexica y por otro se condena el lado espiritual, las prácticas religiosas; etiquetadas como paganas y sanguinarias por los misioneros. Para poder ver que a los indígenas se les ha dado la connotación de extranjeros en su propio territorio, es necesario tener la capacidad de percibir las contradicciones políticas existentes, que no son otra cosa que un componente clave de la manipulación ideológica, que está sumergida en desarticular los conocimientos, alejando a los observadores de una comprensión crítica y coherente del mundo en el que viven. La desarticulación del conocimiento en disciplinas produce una anestesia de la conciencia, carente de esta conciencia los individuos no pueden tener una postura política clara. De tal manera que cuando la información les llega, la toman como la verdad y condenan a todo aquel que diga que no es así, llamándolo adversario del bienestar propagado por las instituciones; por eso, los que se encuentran en puestos subalternos consideran que es correcto tomar posturas alienantes porque es la cancha donde están jugando. Esto ocurre porque no tienen la visión para definir y contrastar ficción y realidad. 
Ante lo anterior, sólo se puede decir que la postura política de las escuelas tradicionales -fungir como centros para adoctrinar a maestros y alumnos- debe ser cuestionada y analizada con el objetivo de encausarla hacia su verdadera labor: difundir los valores democráticos que deben practicarse en una sociedad incluyente; así como propagar la utilización de la tecnociencia como mediadora entre la sociedad y la biodiversidad y por último, pero no menos importante, catalizar un proceso que lleve a todas las áreas del conocimiento a ser intermediarias en el diálogo ético que debe tener la especie humana con la naturaleza. Karel Kosík citado por Koham (2004:94) dice que "el problema de las masas no reside en 'el olvido del ser', metafísico y recluido en el corazón recóndito del hombre, sino en la alienación histórica que genera el capitalismo fetichista. ¡El problema a resolver no es metafísico sino histórico y político!”.

\section{Un docente intelectual para la alfabetización reflexiva}

Aprender a leer la realidad tiene mucho que ver con actos de conocimiento, que llevan a la formulación de actos políticos, transformadores de la persona por sí misma y para ella misma; los que le dan una visión más completa de su propio mundo, para que pueda articularlo a otros mundos a partir de sus propios análisis críticos. El logro de aprehender a tener conciencia de uno mismo tiene la utilidad de llevar a participar, a los individuos, en la definición de las realidades políticas, económicas, culturales y religiosas que les afecten; es, a final de cuentas, una necesidad apremiante para entender la actualidad política y, sobre todo para construir estrategias que sirvan para alcanzar un futuro mejor del individuo que está sumergido en una sociedad que lo hace invisible. El desarrollo de la conciencia crítica consiste en analizar la posibilidad de ampliar la democracia del terreno político a los demás terrenos pertinentes: la administración de la riqueza, el entorno natural y la cultura. Uno puede preguntarse, entonces, ¿para qué o para quién es necesario alfabetizar de la manera tradicional? ¿Su función es sólo unir letras; pero sin que se aprenda a entrar a la dinámica del cuidado de sí? ¿Es una herramienta útil para memorizar técnicas y métodos elementos necesarios para convertirnos en asalariados de las "benefactoras" multinacionales? Eduardo Galeano, en su libro "Patas arriba. La escuela del mundo al revés", hace algunas observaciones pertinentes e interesantes sobre las estrategias educativas que no tienen como premisa difundir cómo se debe vivir en una sociedad democrática:

"El mundo al revés premia al revés: desprecia la honestidad, castiga el trabajo, recompensa la falta de escrúpulos y alimenta el canibalismo. Sus maestros calumnian a la naturaleza: la injusticia, dicen, es ley natural. Milton Friedman, uno de los miembros más prestigiosos del cuerpo docente, habla de «la tasa natural de desempleo». Por ley natural, comprueban Richard Herrnstein y Charles Murray, los negros están en los más bajos peldaños de la escala social. Para explicar el éxito de sus negocios, John D. Rockefeller solía decir que la naturaleza recompensa a los más aptos y castiga a los inútiles; y más de un siglo después, muchos dueños del mundo siguen cre- 
yendo que Charles Darwin escribió sus libros para anunciarles la gloria. ¿Supervivencia de los más aptos? La aptitud más útil para abrirse paso y sobrevivir, el killing instinct, el instinto asesino, es virtud humana cuando sirve para que las empresas grandes hagan la digestión de las empresas chicas y para que los países fuertes devoren a los países débiles, pero es prueba de bestialidad cuando cualquier pobre tipo sin trabajo sale a buscar comida con un cuchillo en la mano (Galeano 2001[1998]:9)”.

En el sistema de la escuela al revés (Galeano 2007[1998]) la cultura es transmitida para que el "educando" esté mayormente predispuesto por el gusto burgués y para que desprecie lo tradicional, argumentando que representa el rezago, es refractario, de bajos logros y lleva a los bajos rendimientos (Hopenhayn 2009). Althusser (1990[1988]) argumentó en su libro "Ideología y aparatos ideológicos del estado" que la función de la escuela capitalista consistía en la reproducción de la [ideología de ese tipo de] sociedad y que toda acción pedagógica sería una imposición arbitraria de las clases dominantes.

Ante lo dicho por Galeano se puede afirmar que la educación como sistema de aprendizaje debe asignarse a si misma la ardua labor de generar en las aulas un proceso de concientización que catalice acciones de resistencia contra las diferentes formas de poder, las que deben conformarse como un movimiento social desde el aprendizaje que haga visibles las relaciones de poder para ubicar su posición, encontrar sus puntos de aplicación y los métodos utilizados. Al tener esta radiografía, la construcción de estrategias de resistencia colectivas sería posible. Por lo tanto, debe de partirse de una alfabetización integral como una herramienta que posibilite al ciudadano común y corriente evidenciar por sí mismo la función de los discursos dichos o puestos en marcha - por ejemplo: maquillar de verde a la industria a través de certificaciones espurias, vueltas verdaderas a través de prebendas económicas. Este tipo de alfabetización permanente y reflexiva, mantendría nítida la lectura de la realidad y se podrían establecer y describir las relaciones de los acontecimientos provocados por el discurso con otros acontecimientos, que pertenecen al sistema económico, al campo político o a las instituciones (Foucault 1999[1994]).

Sin embargo, existen limitaciones para llevar a cabo la alfabetización reflexiva, por ejemplo encontrar docentes intelectuales dentro de las Instituciones de Educación Superior es una tarea complicada porque en algunos de los casos, esos docentes, son docentes por accidente, pero no por vocación. En una buena cantidad provienen de las mismas instituciones - han sido estudiantes en ellas - y son reclutados porque se cree que ya conocen - habituados se podría decir - cómo transmitir el conocimiento, pero en el peor de los casos se convierten en docentes a través de espacios heredados o canjeados por favores. La política de selección del profesorado es un proceso caprichoso que navega sin rumbo, quizá sin intención o quizá con la intención de darle al pueblo "una educación”. Aunque lo anterior no es parte de la discusión, se menciona porque afecta profundamente la construcción del pensamiento reflexivo, 
crítico y de análisis; "hace eterna” la misma visión que se inculca a través del curriculum oculto.

Por nuestra parte, creemos que la lectura de la realidad requiere de un docente que tenga la voluntad para modificar su propio pensamiento a través del rompimiento de lo que aparece ante sus ojos como el sentido común; regularmente este sentido común está materializado por las representaciones compartidas dentro de la sociedad, éstas pueden ser lugares comunes de la existencia ordinaria o de representaciones oficiales, a menudo inscritas en instituciones y, por ende, tanto en la objetividad de las organizaciones sociales como en los cerebros (Bourdieu y Wacquant 1995). El cuestionamiento de lo que parece el sentido común le haría adquirir una postura política, que muy probablemente le llevaría a indagar sobre la voluntad de la verdad, tarea que realizan los intelectuales. Sin embargo, el docente en su papel de intelectual tampoco debe perder de vista lo que Michael Foucault sugiere al respecto: "[e]l trabajo de un intelectual no consiste en modelar la voluntad de política de los demás, estriba más bien en cuestionar, a través de los análisis que lleva a cabo en terrenos que le son propios, las evidencias y los postulados, en sacudir los hábitos, las formas de actuar y de pensar, en disipar las familiaridades admitidas, en retomar la medida de las reglas y de las instituciones y a partir de esta reproblematización (en la que se desarrolló su oficio específico de intelectual) participar en la formación de una voluntad política (en la que tiene la posibilidad de desempeñar su papel de ciudadano) (Foucault 2002:9-10)”. Ante esto, podemos afirmar que el deber del docente, como intelectual, es entonces jugar el papel de catalizador de un pensamiento que devele las verdades construidas dentro de las prácticas sociales institucionales; desconstruir el adoctrinamiento que se da al interior del sistema educativo, dejar de ser una correa de transmisión de las ideologías capitalistas, evitar contribuir al proceso a la formación de sujetos -alumnos- de dos categorías: uno, sometido a otro mediante el control y la dependencia; y otro, atado a su propia identidad por la conciencia o el conocimiento de sí mismo. Diseñar estrategias para quitar la asimetría a las relaciones de dominación-sometimiento; donde los sujetos subalternos son sometidos al accionar de las élites (políticas, intelectuales, económicas) - mientras éstas últimas si pueden aspirar a liberar su subjetividad en el cuidado de sí ${ }^{5}$ (Foucault 1996:50-51) practicando la poesía, las bellas artes y las ciencias consumidoras de recursos económicos, ecológicos y sociales.

La alfabetización reflexiva precisa tener un docente que funja como un intelectual que le quite el cerrojo al sistema del educar para domesticar, en este ámbito deben de darse posturas de aprendizaje y aprehendizaje donde los alumnos no sean considerados como un auditorio, sino como un ele-

\footnotetext{
5 “Cuando uno se preocupa del cuerpo, uno no se preocupa de sí. El sí no es el vestir, ni los instrumentos, ni las posesiones. Ha de encontrarse en el principio que usa esos instrumentos, un principio que no es el cuerpo sino del alma. Uno ha de preocuparse del alma: ésta es la principal actividad en el cuidado de sí (Foucault, 1990:59)”.
} 
mento integrante de una comunidad con preocupaciones compartidas - la complejidad social y ecológica - en la que se espera ellos y el educador puedan participar activamente en la construcción de visiones de realidad más apegada a la complejidad de la realidad. Sin embargo, el sistema educativo contribuye al sometimiento y al adormecimiento hasta un punto en el que un estudiante disciplinado y ordenado, acorde a las normas establecidas por políticas alienantes, se convierte en un buen estudiante porque repite al pie de la letra lo "repetido" por el "maestro" y renuncia al pensamiento crítico; adecuándose a los modelos que le ofrece el instructor, contentándose a contenidos impregnados por una ideología que impone los intereses de la élite dominante.

Replantear el proceso de alfabetización necesita de dos aspectos importantes: por un lado, los alumnos y maestros deben considerar alfabetizarse sobre sus historias, experiencias y sobre todo con respecto a la cultura del entorno inmediato, por el otro lado deben apropiarse de los códigos y culturas de los círculos dominantes, para poder trascender sus propios entornos (Freire 1999:65). Es la toma de conciencia una de las partes importantes para poder contextualizar la realidad propia y la realidad en la que uno está sumergido, sólo a través de la práctica social donde el cuidado de sí (Foucault 1990) debe ser el punto de partida, este cuidado de sí implica tomar conciencia de sí mismo, con la finalidad de que las cosas dejen de ser estímulos para convertirse en retos. En esta línea de pensamiento, se puede decir que alfabetizar es un proceso de toma de conciencia, donde ésta se libera para que el analfabeto se asuma sujeto de su historia personal; pero también de la historia social. El proceso implica posicionarse más adecuadamente en su momento y en su realidad social, con el mundo.

Sin embargo, es importante considerar que las escuelas no son lugares neutrales. Dentro de ellas, se debate una serie de posturas políticas que, regularmente, son definidas en el salón de clases. Por mencionar alguno de estos aspectos, la institución puede tener como política particular introducir una postura religiosa que tenga el objetivo de que los alumnos, al egresar, impregnen sus actividades personales y profesionales con ella. Lo mismo puede suceder con la emisión de una política institucional que declare la importancia de incluir aspectos sociales y ecológicos que tengan como hilo conductor la democracia, la participación social y la justicia social, entre otros aspectos. Lo anterior se encuentra en el plano de lo subjetivo; pero existen implicaciones que se presentan desde el plano de lo objetivo como el interés de introducir o eliminar una serie de materias que definen qué tipo de ciudadano - que ostentará una profesión - estará produciendo una institución. Por lo tanto, es de vital importancia concebir a las instituciones educativas como lugares económicos, culturales y sociales que al mismo tiempo están profundamente ligadas a los temas de poder y control, ya que no se limitan a transmitir de manera objetiva un conjunto común de valores y conocimientos; sino que las escuelas son lugares que representan formas de conocimiento, y usos lingüísticos, relaciones sociales y valores que implican selecciones y exclusiones particulares a partir de la cultura 
general, como tales sirven para introducir y legitimar formas particulares de vida social (Giroux 1990).

Ante lo anterior el papel del docente es limitado porque tiene que seguir una serie de normas y reglas para poder seguir manteniéndose dentro de un empleo. Sin embargo, es claro que el profesor no puede seguir fungiendo el papel de técnico superior encargado de llevar a cabo dictámenes y objetivos decididos por expertos totalmente ajenos a las realidades cotidianas de la vida en el aula. La naturaleza de las reformas educativas de cualquier índole, ya sea emitida a nivel particular o desde la esfera pública- deben ser analizadas y criticadas por el profesor que trabaja cotidianamente con los alumnos. Sin embargo, es necesaria una definición profunda del papel del docente dentro del aula ya que es necesario que este actor social deje de ser el transmisor de conocimientos etiquetados. Hasta hoy, la pedagogía no ha invitado a "conocer el conocimiento anterior para que al reconocer las limitaciones de este conocimiento, [el alumno] conozca más. Por el contrario, [lo que el docente ofrece y] propone es la recepción pasiva de un conocimiento empaquetado." ${ }^{6}$ (Gadotti 2008 [1998]:279). Sí la función de las instituciones de educación es dar a conocer cómo se vive en las sociedades democráticas, entonces debería de abandonar la idea de hacer del profesor un "obrero" que sólo aplique instrumentalmente los contenidos temáticos de una asignatura, siguiendo las indicaciones de "manuales pedagógicos o técnicos" que tienen la función de gestionar y poner en marcha programas curriculares; los que el docente no desarrolló y que no le dejan margen de asimilarlos de manera crítica, sólo los tiene que aplicar, esa es la consigna. Sí por el contrario, el docente establece como política personal ser un intelectual reflexivo, estos programas curriculares proporcionados por las autoridades serían adecuados a la realidad circundante, a la pertinente, a esta que emana de su ambiente local. Si el docente lo decide puede hacer del aula un espacio político en el que tiene la oportunidad de expresar su solidaridad hacia sí mismo y hacia los otros. En este sentido, por ejemplo, si el docente tiene como sueño personal la modernización capitalista, la información que lleve a los alumnos tendrá ese toque y promoverá una capacitación técnica meramente instrumentalista para que pueda estar acorde al "mercado de trabajo". Empujando al alumno a convertirse en un objeto que podrá ser colocado en una vitrina, adornado con leyendas que definan sus habilidades para que pueda ser reclutado por alguna empresa. Sin embargo, si el profesor es reflexivo creará estrategias -con los elementos que se le proporcionen- que alejen al alumno de memorizar "historias técnicas" enajenadas y enajenantes; animándolo a construir sus propias historias y estrategias profesionales y sociales para el cuidado de sí a través de la lectura de la realidad propia y colectiva.

Sin embargo, es preocupante ver en la actualidad una creciente diáspora del desarrollo de ideologías instrumentales que acentúan el enfoque

${ }^{6} \mathrm{El}$ destacado en negritas es de los autores. 
tecnocrático en la formación de profesores y de la pedagogía que deben aplicar. En este momento las instituciones de educación se encuentran inmersas en procesos de estandarización del conocimiento en las que se devalúa el trabajo crítico e intelectual del académico y de los estudiantes para dar cabida total a las consideraciones prácticas. El profesor en este contexto es sólo un ejecutor de leyes y principios de aprendizaje efectivo por lo que su alcance es limitado porque está definido por otros quienes basan tal definición en la investigación sobre la efectividad de los enseñantes. Esta postura está dominada, desde hace tiempo, por una orientación conductista y por el énfasis en el dominio de áreas de asignatura y métodos de enseñanza y no de aprendizaje. El profesor se entretiene en el "cómo enseñar”, “con qué libros” hacerlo, o el dominio de la mejor manera de transmitir un cuerpo dado de conocimientos, esto hace que la autonomía del docente, con respecto al desarrollo y planificación de los currículos, esté reducida a una pragmática forma de dar clases, donde este actor social busca con mucho afán dentro del aula, chicos buenos, pero con la connotación de chicos tranquilos. En estos términos y dentro de esta mística es definido como "aprendizaje" que no es otra cosa que el trabajo dedicado a la elaboración de tareas rutinarias y memorísticas y el cumplimiento del tiempo definido en un horario, constatado por la presencia anestesiada del alumno dentro del salón de clase, como "la meta de enseñanza”.

El postulado teórico de las metodologías reduccionistas es que todos los estudiantes pueden aprender utilizando los mismos materiales, las mismas técnicas de enseñanza - más no de aprendizaje - y las mismas modalidades de evaluación. La pedagogía dominante no toma en cuenta que los estudiantes presentan diferentes historias y encarnan diferentes experiencias, prácticas lingüísticas, culturales y de talentos, dejando de lado la importancia de que la sociedad está compuesta por un profundo contexto de diferenciación debido a la composición social y ecológica en las que se han desarrollado. Si los docentes no son libres en el pensamiento, refuerzan este tipo de enseñanza estilo McDonald’s: rápida, racionada, estandarizada y disciplinada; por el contrario si los docentes son profesionales reflexivos, se consideran a ellos mismo como mujeres y hombres libres con una especial dedicación a los valores de la inteligencia y el exaltamiento de la capacidad crítica de los jóvenes. Los académicos por lo tanto deben realizar el ejercicio docente de manera responsable, participando activamente en el planteamiento de cuestiones serias acerca de lo que ellos mismos enseñan, sobre la forma en la que deben enseñarlo y sobre los objetivos generales que persiguen. Pero dentro del contexto homogenizante esta tarea resulta casi imposible debido a la cantidad de trabajo, traducida en el apabullante número de cursos y alumnos que se le asigna al profesor como carga académica, aunado a que tienen escasa influencia sobre las condiciones ideológicas de su trabajo.

Es asombroso ver cómo algunos profesores logran producir literatura a pesar de la gran carga de trabajo porque lo hacen durante su tiempo libre, en sus hogares, tomando tiempo familiar; pero su esfuerzo productivo está regularmente encausado a crear libros técnicos que fortalecen la 
finalidad instrumentalista de la escuela. No es el afán criticar ese esfuerzo notable, sino es una veta que hay que aprovechar. Es decir, esos docentes pueden seguir creando literatura técnica; pero se necesita "alfabetizarlos" para que incluyan el espíritu reflexivo en ellos; enmarcándolos en la realidad de la complejidad local o nacional para que sean alternativas de soluciones reales. Así, estarían pensados para contribuir en la conformación de una reconciliación entre los mismos humanos y (re)encuentro entre la naturaleza y los seres humanos. "[Un] individuo no puede entablar estrecha relación con su humanidad en tanto no se disponga a trascender su sociedad y a reconocer de qué modo ésta fomenta o estorba sus potencialidades humanas. Si le resultan $<<$ naturales $>>$ las prohibiciones, las restricciones y la adulteración de los valores, es señal de que no tiene un conocimiento verdadero de la naturaleza humana (Fromm, 2007[1992]: 134-135).

Consideramos que se nos debemos estar consciente de que existe una urgencia de replantear la función social de los profesores, el papel que han tenido hasta ahora debe transformarse ya que su función es la de docentes intelectuales porque, a partir de su participación como actores que intervienen en la construcción de pensamientos de cómo es y será la sociedad, se construirán luchas alternas que darán como resultado nuevas visiones que emancipen las visiones de control y poder existentes. El docente debe de estar formado para poder tomar la decisión política de alejarse de las estructuras educativas conductistas y así alfabetizar a los individuos de manera holística a través de estrategias que encarnen una pedagogía imbricada en intereses políticos liberadores del sujeto (Freire, 2001). Los docentes, en este ambiente liberador, deben tomar en serio la necesidad de conceder a los estudiantes voz y voto en las experiencias de aprendizaje. Además, tienen toda la posibilidad de contribuir en la formación de hombres integrales, de acompañarlos a desarrollar sus potencialidades, para que se conviertan en sujeto de su propia historia y no objeto de ella (Gadotti, 2008[1998]).

El planteamiento anterior nos lleva a decir que debe de extenderse una postura política que defienda la transformación de las instituciones de educación en organismos que tienen un contrato social para el mantenimiento y el desarrollo de una democracia incluyente; pero no debe perderse de vista que deben ser instituciones promotoras de un profesorado que funcione como intelectual reflexivo para que acompañe al alumno en el proceso de conversión de ciudadanos reflexivos y activos para participar en la definición y/o cancelación de políticas públicas que le afecten. Por lo tanto, los alumnos deben de considerarse individuos -no seres sujetos a la objetividad homogenizante- que están inmersos en contextos culturales y clases sociales diversos, diferentes y complejos, en este universo donde la realidad es compleja, también están sus sueños, problemas, esperanzas y aspiraciones. La alfabetización reflexiva compartida por los docentes intelectuales debe transformar y sobre todo desarrollar discursos que conjuguen el lenguaje de la crítica y la posibilidad. Entendida esta posibilidad como un esfuerzo para producir cambios que lleven a un bienestar donde la democracia y la justicia social estén presentes. Para ello, los docentes inte- 
lectuales deben pronunciarse contra aquellas realidades donde existan las injusticias ecológicas, económicas, políticas y sociales, tanto dentro como fuera de las instituciones de educación. Equivalentemente a lo anterior, deben de hacer el esfuerzo de construir ambientes y condiciones que proporcionen a los alumnos oportunidades de convertirse en ciudadanos con el conocimiento, la voluntad y el coraje para luchar para que la desesperanza resulte algo inadecuadamente convincente y la esperanza algo prácticamente alcanzable.

Este documento no tiene la intención de definir una técnica de enseñanza o la instrumentación de este proceso, su finalidad es hacer una contribución en la que planteamos la necesidad de crear formas que lleven a "pensar" los contenidos de las asignaturas: sus repercusiones y los amarres que hacen en los alumnos; sin dejar de mencionar el destino que el curriculum oculto les designa. Sin embargo, consideramos que es importante hacer algunas sugerencias que nos den una luz sobre cómo poner en práctica estos espacios reflexivos entre el profesor y el alumno implica agregar tiempo a los programas temáticos. Para ello se puede recurrir a un cierto número de posibles "instrumentaciones" como: i) las tareas deben además de cumplir con los objetivos "técnicos", propiciar "escuchar” la voz de los alumnos a través de sus aportaciones, motivándolos a que expresen sus posturas contrastando la teoría con la realidad; ii) la práctica de laboratorio, considerarla una oportunidad para incluir una reflexión crítica sobre los beneficios o perjuicios que la aplicación de las técnicas llevaría a la sociedad, asimismo buscar métodos alternativos, adecuados a la sociedad y a los ecosistemas, detallando su contexto y su aplicación futura; iii) la evaluación a través de rúbricas favorece el trabajo en equipo donde el alumno tiene la oportunidad de comparar sus ideas con las compartidas por sus colegas-alumnos. El docente intelectual dentro de esta actividad motiva para que se den procesos de democratización y respetaría el resultado, independientemente de que esté o no de acuerdo, él evaluaría reflexión crítica y la participación activa de cada uno dentro de una tarea grupal; iv) la inclusión de visitas a empresas de diferente índole deben de propiciar reflexiones sobre sus impactos positivos o negativos en la sociedad y los ecosistemas. Además, deben ser fuente para hacer debates que lleven a análisis de las posibles soluciones a los problemas que conlleva implantar procesos que producen externalidades sociales y ecológicas; v) el desarrollo de simulaciones educativas a través de actividades de animación sociocultural donde se recree una problemática socioecológica ficticia (Santiago y Arroyo 2007). La riqueza de esta herramienta en la posibilidad de incluir conocimientos de una manera interdisciplinaria y multicultural, como una práctica de la lectura de la realidad y su complejidad.

Finalmente, creemos que la alfabetización reflexiva será posible a partir de la definición de una postura política solidaria, democrática e incluyente de la red de actores sociales que convergen en la formación de seres humanos. 


\section{Conclusiones}

Es una idea generalizada creer que un individuo está alfabetizado porque conoce la técnica de leer y escribir; pero cuando se encuentra ante la complejidad de la realidad no puede distinguir entre la verdad y la voluntad de la verdad (Foucault 2009[1973]) consecuentemente no puede leer esa complejidad, mucho menos puede escribir sobre ella o mantener un diálogo para determinar socialmente la importancia que tiene para él mismo "el cuidado de sí”. Estas limitantes tampoco le permiten decodificar los mitos creados para homogenizar y colonizar el pensamiento del ciudadano común. Descifrar la realidad dentro de la complejidad social y ecológica existente necesita examinar las diferentes maneras en las que el discurso como una función política de subyugación- desempeña un papel dentro de un sistema estratégico en el que el poder está implicado y gracias al cual funciona. Es decir, el discurso -sea cual sea- necesita del ejercicio del poder para funcionar. (Foucault 1999[1994]). Por su parte, la enseñanza, como sistema estratégico, hace funcionar los discursos dominantes a través de procesos de modernización que hablan de su apertura al mundo actual. Sin embargo, lo que en el fondo se busca es mantener el viejo sustrato tradicional y favorecer el aprendizaje rápido y eficaz de un cierto número de técnicas modernas que buscan el desarrollo de esta sociedad; sin embargo, lo hace de manera desigual.

Leer la realidad compleja significa, separar y reordenar las piezas fragmentadas que bullen en los medios de información y son transmitidas por las instituciones como mitos históricos. Por lo tanto, la adquisición de la suficiente lucidez para este proceso exige un alto nivel de claridad política, un aspecto trascendente que la ideología dominante elimina de los currículos de casi todas las disciplinas. Se puede observar que las personas educadas a través de un modelo de transferencia de conocimiento, no son capaces de relacionar aspectos subyugantes en las políticas públicas que tienen que ver con el campo mexicano, por ejemplo, cuestionar si la promoción del monocultivo de Jatropha curcas para la producción de biodiesel beneficia a la sociedad, no logran visualizar que la conversión de los campos cambiará de manera drástica los ecosistemas, agravando los problemas ecológicos existentes. Sólo se puede ver un alivio maquillado de verde que sostendrá por más tiempo al sistema civilizatorio prevaleciente. Esta anestesia de la conciencia es uno de los componentes centrales de la pedagogía dominante que lleva a impedir el desarrollo de una comprensión crítica de la realidad. Chomsky (2007) le llama a este proceso la creación de ilusiones necesarias y simplificaciones a gran escala y de gran poder emotivo para que el "rebaño desconcertado" no se vea aturdido por la complejidad de los problemas reales que, además, tampoco sabría cómo resolver

Lo anterior nos hace decir que sin lugar a dudas, la alfabetización y la educación, hasta ahora, han sido "un proceso técnico" que tiene el objetivo de aprehender a unir letras para que los sujetos las utilicen en su acondicionamiento a las formas económicas y sociales hegemónicas. En este contexto teórico el docente funge como técnico superior encargado de lle- 
var a cabo dictámenes y objetivos decididos por expertos totalmente ajenos a las realidades cotidianas de la vida en el aula. Para que el docente deje de representar ese papel, es necesario construir una definición profunda de su rol dentro del aula para que deje de ser una correa que sirve como fuente consolidante de conocimientos etiquetados por estructuras políticas enquistadas en la trama dominante. Asimismo, se le pediría que no siga a pie juntillas las indicaciones de “manuales pedagógicos” que gestionan y ponen en marcha programas curriculares, sin que los desarrolle o asimile críticamente. Contrariamente, en su papel de intelectual reflexivo, los ajusta a la realidad circundante que emana de su ambiente local. Para que el cambio sea profundo es necesario transformar a las instituciones de educación para que se conviertan en organismos que mantengan y desarrollen una democracia incluyente, donde se transformen a los alumnos en ciudadanos reflexivos y activos para que participen activamente en la definición y/o cancelación de políticas públicas que le afecten.

Una alfabetización más allá de la mera técnica de unir vocales y consonantes, debe consistir en la formulación de diálogos que sirvan para catalizar ciertos grados de conciencia de uno mismo ante la realidad. Reflexionando sobre qué sería el acto de aprender a leer y escribir, se puede decir que tiene que partir de una profunda comprensión de leer una realidad circunscrita en la complejidad (Freire 1989 [1987]); pero debe existir un profundo interés de cuidar de sí (Foucault 1990). En este documento no se está proponiendo el abandono de la técnica, sino la inclusión de estrategias de aprendizaje que lleven a los sujetos a leer la realidad para poder acercarse a la complejidad de una manera más adecuada a su propia realidad.

Los docentes como profesionales reflexivos de la enseñanza deben de considerarse o deberían considerarse como mujeres y hombres libres con una especial dedicación a los valores de la inteligencia y el exaltamiento de la capacidad crítica de los jóvenes. Dentro de esta conceptualización teórica se insiste en que los académicos deben realizar el ejercicio responsable, participando activamente en el planteamiento de cuestiones serias acerca de lo que ellos mismos enseñan, sobre la forma en la que deben enseñarlo y sobre los objetivos generales que persiguen.

En estos tiempos de crisis nace la urgencia de promover y recuperar aquella postura del profesor como intelectual transformador y reflexivo. Un docente con capacidad para pensar la sociedad, para reflexionar sobre su quehacer y construir un discurso que conjugue el lenguaje de la crítica con el de la posibilidad de hacer cambios en su propia realidad, así como en la local, nacional e internacional. Por lo tanto, es vital diseñar estrategias que catalicen una postura política incluyente, justa, democrática y como propone Freire (1989[1987]) emancipadora en los profesores para que se perciban a sí mismos con posibilidades para enfrentar, constructivamente, las tensiones y la complejidad del mundo social y se reconozcan como actores sociales con capacidad para abordar e introducir transformaciones en la escuela y en los procesos de formación de los seres humanos que tienen a su cargo. El profesor que con ilusión espera cada quincena su paga, 
es dueño de un saber que puede usar para problematizar su relación con el conocimiento, con los alumnos y con el contexto social y político en el cual desempeña su labor, ante esta potencialidad de poder transformar la historia, no puede entonces limitarse a transmitir conocimientos, a seguir pasivamente la secuencia de los programas establecidos. Al ser dueño de un saber puede crear panoramas intelectuales que no sólo tengan un contexto instrumentalista técnico, sino que puede vestirlo con la filosofía, la política y la investigación, de esta manera el tomaría la decisión política de convertirse en mediador entre el saber cotidiano y el saber científico, traducir e integrar estos saberes en función de los cambios y las transformaciones sociales que la escuela y el país necesitan. 


\section{Bibliografía}

Althusser, Louis (1990 [1988]), Ideología y aparatos ideológicos del estado, Ediciones Quinto Sol, México.

Bauman, Zygmunt (2008 [1998]), Trabajo, consumismo y nuevos pobres, Gedisa editorial, España.

Bourdieu y Wacquant (1995), Por una antropología reflexiva, Editorial Grijalbo, México.

Chomsky, Noam (2007[2000]), La (des)educación, Biblioteca de bolsillo, España.

Escobar, Arturo (1995), Encountering development: the making and unmaking of the third world, Princenton University Press, New Jersey.

Freire, Paulo (2001), Educación y actualidad brasileña, Siglo XXI Editores, México.

Freire, Paulo y Donaldo Macedo (1989 [1987]), Alfabetización. Lectura de la palabra y lectura de la realidad, Ediciones Paidós Ibérica, S.A., España.

Foucault, Michel (2002), La hermenéutica del sujeto. Curso en el Collège de France (1981-1982), Fondo de Cultura Económica, Argentina.

Idem (2009 [1973]), El orden del discurso, Fábula TusQuest Editores, México.

Idem (1999[1994]), Estética, ética y hermenéutica. Volumen III, Ediciones Paidós Ibérica, S. A. España.

Idem (1990), Tecnologías del yo y otros textos afines, Ediciones Paidós Ibérica, S. A., España.

Fromm, Erich (2007 [1992]), El humanismo como utopía real, Paidós Ibérica, S. A., España.

Gadotti, Moacir (2008[1998]), Historia de las ideas pedagógicas, Siglo XXI editores, México.

Galeano, Eduardo (2007[1998]), Patas arriba. La escuela del mundo al revés, Siglo XXI Editores, México.

Giroux, Henry (1990), Los profesores como intelectuales, Paidós Ibérica, S. A., Barcelona.

Gramsci, Antonio (2000), Los intelectuales y la organización de la cultura, Ediciones Nueva Visión, Buenos Aires. 
Hopenhayn, Martín (2009), "La educación intercultural: entre la igualdad y la diferencia” en Pensamiento Iberoamericano. Número 4. 2 a época, Agencia Española de Cooperación Internacional para el Desarrollo - Fundación Carolina, Madrid, Disponible a texto completo en: www. pensamientoiberoamericano.org/.../pensamientoIberoamericano-95.pdf. Consulta del 12 de agosto de 2009.

Kohan, Néstor (2004), “La filosofía militante de Karel Kosík (1926-2003)” en UPL. Dic. 2004, vol.9, no.27, p.87-95. Disponible a texto completo en: http://www.serbi.luz.edu.ve/scielo.php?script=sci_arttext\&pid=S131552162004012000008\&lng=es\&nrm=iso. Consultado el 31 de agosto de 2009.

Kosik, Karel (1991), El individuo y la historia, Editorial Almagesto, Buenos Aires.

Reichmann, Jorge (2004), Ética ecológica. Propuestas para una reorientación, Editorial Nordan-Comunidad, Montevideo.

Santiago, Evelinda y Gloria Arroyo (2007), “Asignatura sello CTS+I: estrategia para la alfabetización tecnocientífica”, en Revista de la Educación Superior Vol. XXXVI (4). Número 144. Octubre-Diciembre de 2007. ANUIES, México, p.87-98. Disponible a texto completo en: http:// redalyc.uaemex.mx/redalyc/pdf/604/60414405.pdf 